\title{
Impact of Singapore's COVID-19 control measures on home-based physical activity in children
}

\section{Dear Editor,}

Children and adolescents, with age ranging from 5 to 17 years old, are recommended to accumulate an average of 60 minutes per day of moderate- to vigorousintensity physical activity (PA) across the week, and to include muscle- and bone-strengthening activities for at least 3 days per week. ${ }^{1}$ School-going children in Singapore were confined to their homes for 7 continuous weeks due to the circuit breaker, the national lockdown measures to curb the spread of COVID-19. We conducted a retrospective study to describe the characteristics of home-based PAs that these children engaged in, and the challenges of home-based PAs encountered during the circuit breaker.

An online survey was conducted for a month in June 2020, after the lifting of the circuit breaker. The study recruited primary and secondary school students (aged 7 to 17 years old), and surveyed their activities in the preceding 7 weeks during the circuit breaker. The survey was disseminated to the public via KK Women's and Children's Hospital's social media channels and posters placed within the hospital premises. The survey consisted of 6 sections: demographics, characteristics of PA, home-based learning (HBL), use of electronic devices for PA, sedentary behaviour (SB), and safety and challenges encountered when doing home-based PAs. The questions, were based on international PA questionnaires and modified to suit the local context.,3

All participants provided informed assent and parental informed consent. All responses were also anonymised. The study was exempted from SingHealth Centralised Institutional Review Board (CIRB Ref. No: 2020/2542). Data were analysed using crosstabulations and association of the variables was tested using chi-square test. A $P$ value of less than 0.05 was considered statistically significant. Analyses were performed using SAS software version 9.4 (SAS Institute Inc, Cary, US).

There were 296 responses: $61 \%$ were primary school (PS) students and 59\% were girls. The majority (63\%) lived in public Housing and Development Board flats, followed by $27 \%$ in private condominiums and apartments, and $10 \%$ in landed houses. More than half (60\%) reported doing PAs from 1 to 3 days weekly and the most frequent PA duration was 15-30 minutes per day $(32 \%)$. In terms of intensity, $77 \%$ reported their PAs as moderate or vigorous. Overall, only $4 \%$ of PS and $5 \%$ of secondary school (SS) students met the daily PA recommendation. PS and SS students engaged in different types of PA as $48 \%$ of PS students did aerobic activities, whereas $51 \%$ of SS students did muscle-strengthening activities. More PS students $(72 \%)$ also required a partner when doing PAs. Threequarters of the participants received HBL physical education sessions and most sessions (78\%) were held once or twice per week.

Almost three-quarters (74\%) of the respondents used electronic devices for PAs. The computer was most frequently used $(50 \%)$, followed by the handphone (24\%); there was higher usage of handphone for PAs in SS (38\%) students. Online streaming, such as YouTube, was the most popular medium (59\%). With regards to SB, most (35\%) spent 2 to 4 hours in SB daily but more SS students (29\%) reported above 6 hours of SB.

Only $4 \%$ of the participants sustained injuries when doing home-based PAs and the injuries were musculoskeletal or blunt trauma in nature. The 2 main challenges encountered were the lack of space $(38 \%)$ and lack of motivation (15\%). On the whole, home-based PAs received slightly favourable ratings as the overall satisfaction mean score was 5.5, based on a 10-point Likert scale (0: least satisfactory; 10: most satisfactory). The survey results are summarised in Table 1 .

Studies on the PA levels of Singapore children and adolescents before COVID-19 showed a worrisome trend as they could only meet $40 \%$ of the PA recommendation at best, ${ }^{4}$ but a more recent study by Ting et al. showed that 0 out of 233 adolescents achieved the daily PA recommendation..$^{5}$ Our study revealed that the lockdown measures further curtailed school-going children PAs as most $(95 \%)$ were unable to achieve the recommended amount of PAs. Contributing factors include the lack of outdoor activities and organised sports, limited access to recreational facilities, and inability to do PAs with friends. ${ }^{6}$ Although distance-based PA programmes in selected patient groups had equivocal results, ${ }^{7}$ our findings suggested that HBL probably created opportunities for home-based PAs, as more than half reported the same frequency of PA sessions for both home-based PAs and HBL. 
Table 1. Correlations of education level with characteristics of physical activities, electronic device and media use, sedentary behaviour and safety concerns and challenges encountered (expressed as a percentage within each level)

\begin{tabular}{|c|c|c|}
\hline \multicolumn{3}{|c|}{ Characteristics of home-based physical activities (PA) } \\
\hline Frequency (per week) & Primary school & Secondary school \\
\hline 1 day & 21.5 & 20.9 \\
\hline 2 days & 17.1 & 22.8 \\
\hline 3 days & 20.9 & 16.1 \\
\hline 4 days & 10.4 & 11.4 \\
\hline 5 days & 11.0 & 9.5 \\
\hline 6 days & 4.4 & 4.7 \\
\hline 7 days & 14.3 & 14.2 \\
\hline
\end{tabular}

Duration (per day)

\begin{tabular}{|c|c|c|}
\hline$<15$ min & 22.6 & 16.1 \\
\hline $15-30 \mathrm{~min}$ & 34.8 & 31.4 \\
\hline $30-45 \mathrm{~min}$ & 22.6 & 16.1 \\
\hline $45-60 \mathrm{~min}$ & 10.4 & 20.0 \\
\hline$>60 \mathrm{~min}$ & 9.3 & 16.1 \\
\hline \multicolumn{3}{|l|}{ Intensity } \\
\hline Light & 24.8 & 19.0 \\
\hline Moderate & 64.0 & 62.8 \\
\hline Vigorous & 11.0 & 18.0 \\
\hline
\end{tabular}

\section{Main type of $\mathbf{P A}^{\mathrm{a}}$}

$\begin{array}{lcc}\text { Muscle-strengthening activities } & 22.0 & 51.4 \\ \text { Aerobic activities } & 48.0 & 21.9 \\ \text { Ball games } & 5.5 & 4.7 \\ \text { Racket games } & 2.2 & 4.7 \\ \text { Others } & 22.0 & 17.1\end{array}$

\section{Physical activity partner ${ }^{\mathrm{a}}$}

Yes $\quad 72.3$

Electronic device and media used for PA

\section{Electronic device}

\begin{tabular}{|c|c|c|}
\hline Yes & 74.5 & 74.2 \\
\hline No & 25.4 & 25.7 \\
\hline \multicolumn{3}{|l|}{ Type of device ${ }^{a}$} \\
\hline Television & 8.1 & 1.2 \\
\hline Computer & 52.5 & 48.7 \\
\hline Tablet & 20.0 & 7.6 \\
\hline Handphone & 14.8 & 38.4 \\
\hline Wearable device & 0.7 & 0.0 \\
\hline
\end{tabular}


Table 1. Correlations of education level with characteristics of physical activities, electronic device and media use, sedentary behaviour and safety concerns and challenges encountered (expressed as a percentage within each level) (Cont'd)

\begin{tabular}{|c|c|c|}
\hline \multicolumn{3}{|c|}{ Characteristics of home-based physical activities } \\
\hline Frequency (per week) & Primary school & Secondary school \\
\hline \multicolumn{3}{|l|}{ Type of device ${ }^{a}$} \\
\hline Game console & 2.2 & 3.8 \\
\hline Others & 1.4 & 0.0 \\
\hline \multicolumn{3}{|l|}{ Type of media } \\
\hline Online stream & 61.4 & 56.4 \\
\hline Social media & 2.2 & 8.9 \\
\hline Mobile application & 13.3 & 11.5 \\
\hline Video game & 5.9 & 5.1 \\
\hline \multicolumn{3}{|l|}{ Sedentary behaviour } \\
\hline \multicolumn{3}{|l|}{ Total time (per day) ${ }^{a}$} \\
\hline$<2$ hours & 32.5 & 17.1 \\
\hline $2-4$ hours & 33.7 & 37.1 \\
\hline 4-6 hours & 20.9 & 20.9 \\
\hline $6-8$ hours & 7.7 & 16.1 \\
\hline$>8$ hours & 4.9 & 8.5 \\
\hline \multicolumn{3}{|c|}{ Safety concerns and challenges encountered } \\
\hline \multicolumn{3}{|l|}{ Injury encountered } \\
\hline No & 97.7 & 94.2 \\
\hline \multicolumn{3}{|l|}{ Challenge encountered } \\
\hline Lack of time & 2.5 & 7.4 \\
\hline Lack of space & 64.7 & 41.9 \\
\hline Lack of equipment & 9.2 & 13.5 \\
\hline Lack of electronic device & 0.8 & 1.2 \\
\hline Lack of partner & 3.3 & 3.7 \\
\hline Lack of knowledge & 0.8 & 1.2 \\
\hline Lack of skill & 2.5 & 0.0 \\
\hline Lack of motivation & 14.2 & 30.8 \\
\hline Others & 1.6 & 0.0 \\
\hline
\end{tabular}

a $P<0.05$

The study highlighted 2 differences in home-based PAs between PS and SS students. Firstly, PS students mainly engaged in aerobic PAs, such as running, while SS students mostly participated in muscle-strengthening
PAs, such as push-ups. This could be related to the misconception that muscle-strengthening PAs is unsafe for young children and thus the lack of exposure. ${ }^{8}$ Secondly, more PS students engaged in PAs with a 
partner and Keyes et al. also reported that parents need to be active in the presence of their children. ${ }^{9}$ Electronic devices and online media are essential tools for distance-based connections. ${ }^{10}$ This was reflected in the study as almost three-quarters of the participants used electronic devices and online media for homebased PAs. These findings may highlight certain considerations when designing home-based PAs for the respective educational levels and the required equipment or resources.

A major concern was high SB during the circuit breaker as $73 \%$ of participants exceeded 2 hours of daily SB and the current World Health Organization recommendation was to limit $\mathrm{SB}$, particularly in recreational screen time. ${ }^{1}$ The excessive amount of SB in Singapore adolescents found in previous studies was also evident in our study as higher proportion of SS students reported SB above 2 hours daily. ${ }^{5,11}$ Another concern was the injury risk due to the limited space of most homes in Singapore. The study showed that home-based PAs could be performed safely as only $4 \%$ reported musculoskeletal or blunt trauma injuries. To minimise these concerns, home-based PA programmes should include instructions to reduce SB and injury risks. ${ }^{12}$

This study has certain limitations. The survey was subjected to recall bias, and recruitment was only possible after lifting of the circuit breaker due to logistical difficulties. The design of our study, which used subjective measures, limited the comparison with previous studies, which used objective measures. Participants tended to over-report their PA level in surveys. ${ }^{4}$ The participants formed a small representation of all school-going children in Singapore and a larger sample size would be more ideal.

Lockdown measures were necessary to curb the spread of COVID-19 but they significantly limited PAs in school-going children. The study showed that school-going children were receptive towards and able to adapt to home-based PAs. These findings revealed certain considerations and required resources when designing home-based PAs, including HBL, as we support children and adolescents to achieve adequate PAs in the current pandemic.

\section{Acknowledgement}

The authors would like to thank Dr John Carson Allen Jr from the Centre for Quantitative Medicine, Duke-NUS Medical School, for his support in this study.

\section{REFERENCES}

1. World Health Organization. WHO guidelines on physical activity and sedentary behaviour, 25 November 2020. Available at: https:// www.who.int/publications/i/item/9789240015128. Accessed on 25 November 2020.

2. World Health Organization. Global physical activity questionnaire (GPAQ) analysis guide V2 Available at: https:/www.who.int/ncds/ surveillance/steps/GPAQ\%20Instrument $\% 20$ and $\% 20$ Analysis $\% 20$ Guide\%20v2.pdf. Accessed on 10 May 2020.

3. Kowalski KC, Crocker PR, Donen RM. The physical activity questionnaire for older children (PAQ-C) and adolescents (PAQ-A) manual, August 2004. College of Kinesiology. University of Saskatchewan. Available at: https://www.researchgate.net/profile/ Peter-Crocker/publication/228441462_The_Physical_Activity_ Questionnaire for Older Children PAQ-C and Adolescents PAQ-A_Manual/links/00b $7 \bar{d} 51 \mathrm{a} 37 \mathrm{fe} 8 \overline{8} 69464000000 /$ The-PhysicalActivity-Questionnaire-for-Older-Children-PAQ-C-and-AdolescentsPAQ-A-Manual.pdf. Accessed on 10 May 2020.

4. Chia M. Physical inactivity among children and adolescents in Singapore: A paradoxical issue. Acta Kinesiol 2008;2:7-15.

5. Ching Ting JL, Mukherjee S, Yong Hwa MC. Physical Activity and Sedentary Behavior Patterns of Singaporean Adolescents. J Phys Act Health 2015;12:1213-20.

6. Moore SA, Faulkner G, Rhodes RE, et al. Impact of the COVID-19 virus outbreak on movement and play behaviours of Canadian children and youth: a national survey. Int $\mathrm{J}$ Behav Nutr Phys Act 2020;17:85

7. Mizrahi D, Wakefield CE, Fardell JE, et al. Distance-delivered physical activity interventions for childhood cancer survivors: A systematic review and meta-analysis. Crit Rev Oncol Hematol 2017;118:27-41

8. Guy JA, Micheli LJ. Strength training for children and adolescents. J Am Acad Orthop Surg 2001;9:29-36.

9. Keyes BL, Wilson KS. Influence of Parental Physical Activity and Sedentary Behavior on Young Children: Considering Time Together. Res Q Exerc Sport 2020. doi:10.1080/02701367.2020.1727405

10. Wang G, Zhang Y, Zhao J, et al. Mitigate the effects of home confinement on children during the COVID-19 outbreak. Lancet 2020;395:945-7.

11. Lee KS, Trost SG. Physical activity patterns of Singaporean adolescents. Pediatr Exerc Sci2006;18:400-14.

12. Phelan KJ, Khoury J, Xu Y, et al. A randomized controlled trial of home injury hazard reduction: the HOME injury study. Arch Pediatr Adolesc Med 2011;165:339-45.

Benny KG Loo ${ }^{1}$ MMed (Paeds), Micheal CM $\underline{\operatorname{Lim}}^{2}{ }^{2}$ SC, Joanne SM Gao ${ }^{2} B S c$, Mohammad Ashik Zainuddin ${ }^{3}{ }_{F R C S E d}$

\footnotetext{
${ }^{1}$ Department of Paediatrics, KK Women's and Children's Hospital, Singapore

${ }^{2}$ Sport \& Exercise Medicine Service, KK Women's and Children's Hospital, Singapore

${ }^{3}$ Department of Orthopaedic Surgery, KK Women's and Children's Hospital, Singapore
}

Correspondence: Dr Benny Kai Guo Loo, Department of Paediatrics, KK Women's and Children's Hospital, 100 Bukit Timah Road, Singapore 229899.

Email: benny.loo.k.g@singhealth.com.sg 